\title{
Rare variant of HSPG2 is not involved in the development of adolescent idiopathic scoliosis: evidence from a large-scale replication study
}

\author{
Chao Xia, Leilei Xu, Bingchuan Xue, Fei Sheng, Yong Qiu and Zezhang Zhu*
}

\begin{abstract}
Background: Rare variants of HSPG2 have recently been reported to function as a potential contributor to the susceptibility of adolescent idiopathic scoliosis (AIS) in the Caucasians. A replication study in the different population is warranted to validate the role of HSPG2 in AIS. The aim of this study was to determine the association between HSPG2 and AIS in the Chinese patients and to further investigate its influence on the phenotype of the patients.

Methods: SNVs p.Asn786Ser of HSPG2 was genotyped in 1752 patients and 1584 normal controls using multiple ligase detection reactions. The mRNA expression of HSPG2 in the paraspinal muscles was quantified for 90 patients and 26 controls. The The Student's t test was used to analyze the inter-group comparison of the HSPG2 expression. The relationship between the HSPG2 expression and the curve magnitude of the patients was analyzed by the Pearson correlation analysis.

Results: No case of mutation in the reported SNV p.Asn786Ser of HSPG2 was found in our cohort. The mRNA expression of HSPG2 in patients was comparable with that in the controls $(0.0016 \pm 0.0013$ vs. $0.0019 \pm 0.0012, p=0.29) .42$ patients with curve magnitude $>60$ degrees were assigned to the severe curve group. The other 58 patients were assigned to the moderate curve group. These two groups were found to have comparable HSPG2 expression $(0.0015 \pm 0.0011$ vs. $0.0017 \pm 0.0014, p=0.57)$. And there was no remarkable correlation between the expression level of HSPG2 and the curve severity $(r=0.131, p=0.71)$.
\end{abstract}

Conclusions: HSPG2 gene was not associated with the susceptibility or the phenotypes of AIS in the Chinese population. The whole HSPG2 gene can be sequenced in more AIS patients to identify potentially causative mutations.

Keywords: HSPG2, Rare variation, Adolescent idiopathic scoliosis, Replication

\section{Background}

Adolescent idiopathic scoliosis (AIS) is a complex spinal deformity that affects millions of children worldwide [1]. To benefit the prognosis and therapeutic strategy for patients with AIS, it is crucial to have a clear understanding of the etiopathogenesis of this disease. For the past half century, numerous studies have been carried out to investigate the etiology of AIS while the conclusions remain obscure [2]. Traditionally, AIS is considered as a multifactorial disorder that involves interaction

\footnotetext{
* Correspondence: zezhangzhu@126.com

Department of Spine Surgery, The Affiliated Drum Tower Hospital of Nanjing University Medical School, Nanjing, China
}

between different factors, including genetic susceptibility, growth disturbance, hormones and metabolic dysfunction, abnormal central nervous system and proprioception impairment [3-7]. Among these factors, previous familial studies of AIS have strongly implied the genetic background of AIS $[8,9]$. But to date, the exact inheritance mode of AIS remains unclear.

Confined by the low efficiency to define the genetic markers, whole-genome linkage analysis was firstly used in the genetic research of AIS which could only identify large chromosome regions potentially containing disease-related genes $[10,11]$. Gradually, it became feasible to analyze SNPs through TaqMan real-time quantitative PCR assay,

(c) The Author(s). 2019 Open Access This article is distributed under the terms of the Creative Commons Attribution 4.0 International License (http://creativecommons.org/licenses/by/4.0/), which permits unrestricted use, distribution, and reproduction in any medium, provided you give appropriate credit to the original author(s) and the source, provide a link to the Creative Commons license, and indicate if changes were made. The Creative Commons Public Domain Dedication waiver (http://creativecommons.org/publicdomain/zero/1.0/) applies to the data made available in this article, unless otherwise stated. 
which was a high-throughput method to differentiate the genotype of target variants. Since then, multiple susceptible genes of AIS have been discovered through candidate genetic association studies [12-17]. To be noted, however, few of these genes could be successfully replicated in different populations, which greatly weakened the reliability of such candidate susceptible genes in AIS $[18,19]$. Commonly, ethic differences and small sample size of the patients were considered to underlie the discrepancy between the original and the replication studies $[18,19]$. In addition, the speculation based on which those candidate genes was selected was mostly lack of essential scientific evidence, thus inevitably leading to the failed replication.

To overcome the above-mentioned limitations of candidate genetic association studies, a much powerful tool, genome-wide genotyping chip, was utilized to identify the susceptible gene of AIS [20-26]. Sharma et al. [26] performed the first genome-wide association study (GWAS) in the Caucasians and reported that CHL1 was associated with AIS. In the following decade, more susceptible loci of AIS were discovered in the Caucasian, the Japanese and the Chinese populations through GWAS, including LBX1, GPR126, BNC2, PAX1, LBX1-AS1, BCL2, AJAP1, PAX3, TNIK, MEIS1, and MAGI1 [20-25]. However, only a small proportion of the heritability of AIS can be explained by these common variants.

With the advances of sequencing techniques, more research teams have begun to analyze the role of rare variants in AIS using whole exome sequencing (WES) in recent years [27-29]. With a low minor allele frequency in normal population, rare variants are usually expected to have larger impact on the inheritance of complex disease than common variants. Patten et al. [27] performed the first WES in AIS and reported 3 rare variants of the POC5 functionally associated with AIS. Subsequently, Buchan et al. [28] reported that rare variants in FBN1 and FBN2 could contribute to both risk and severity of AIS. Haller et al. [30] found that rare variants across extracellular matrix genes contributed strongly to the risk of AIS in patients with European ancestry. Overall, identification and validation of rare variants associated with AIS is a promising method to explain the missing heritability of this complex disease.

In a recent study, rare variants of HSPG2 were reported to function as a potential contributor to the susceptibility of AIS in the Caucasians [31]. Obviously a replication study in the different population is warranted to validate the role of HSPG2 in AIS. This study aimed to determine the association between HSPG2 and AIS in the Chinese patients and to further investigate its influence on the phenotype of the patients.

\section{Methods}

\section{Subjects}

Under the approval of the local institutional review board, a cohort of 1752 female AIS patients and 1584 controls were included in the current study. All the patients were excluded to have neurological defect through MRI examination. All the controls were excluded to have scoliosis through Adam's Forward Bend Test using the standard criteria performed by a senior spine surgeon (Z.Z.). Demographic data were collected for each participant, including initial age, curve pattern and curve magnitude measured by the Cobb angle method on the standing posteroanterior X-ray films.

\section{Genotyping of the rare variant}

All the subjects signed the informed consent for the collection of blood samples. Genomic DNA was then extracted with the commercial kit (Qiagen K.K., Tokyo, Japan). Single nucleotide variant (SNV) p.Asn786Ser (rs143736974) of HSPG2 was genotyped for all participants. Allelic-specific multiple ligase detection reactions (LDR) was used for genotyping assay as previously reported, with the primer shown in Table 1. Fifteen percent of the samples were randomly selected for Sanger sequencing to ensure the reproducibility of the LDR results.

\section{Genotyping of common variations in HSPG2}

Common variants covering HSPG2 gene were identified through the Ensemble database (http://www.ensembl.org/index.html). GWAS database that was composed of 1446 AIS patients and 2080 controls was processed with the PLINK (version 1.90, http://zzz.bwh.harvard.edu/plink/tutorial.shtml) to determine the genotyping results of these common variants.

\section{RNA extraction and real-time qPCR}

Ninety-eight female AIS patients were included in the expression analysis of HSPG2. Twenty-eight female lumbar disc herniation (LDH) patients with no presence of spinal

Table 1 Primers for the genotyping assay and expression analysis

\begin{tabular}{|c|c|}
\hline & Primers \\
\hline \multicolumn{2}{|l|}{ p.Asn786Ser } \\
\hline TC & TIITITIITITITTGTTGCACTGTGGCCCCTCCtTGC \\
\hline$\pi$ & TITITITITITITITTGTTGCACTGTGGCCCCTCCtTGT \\
\hline TR & TGTGCTGGCAATTCTAGAAGAAGGAtttttt \\
\hline GAPDH & TIIIIITIAGCTGCAGATCCTGCACCAAGAGC \\
\hline Forward & 5'- GAGTCAACGGATTTGGTCGT - 3' \\
\hline Reverse & 5'- TTGATTTGGAGGGATCTCG - 3' \\
\hline \multicolumn{2}{|l|}{ HSPG2 } \\
\hline Forward & $5^{\prime}$ - TACACACGCCACCTGATCTC - $3^{\prime}$ \\
\hline Reverse & 5' - GCTGCCAGTAGAAGGACTCA -3' \\
\hline
\end{tabular}


deformity were included as the controls. The paraspinal muscle was collected from each subject during the surgery. For AIS patients, we collected the muscle sample from both the concave side and convex side at the apex of the curve. Total RNA was then extracted from the muscle tissue using a commercial kit (CWBio. Co. Ltd). The mRNA expression of HSPG2 was quantified with real-time polymerase chain reaction (PCR) on ABI 7900HT, with GAPDH used as the endogenous control. All amplifications were performed in triplicate. The relative expression of HSPG2 was normalized using the $\Delta \Delta \mathrm{Ct}$ method. The primers of HSPG2 and GAPDH were shown in Table 1.

\section{Statistical analysis}

SPSS version 17.0 (SPSS Inc., Chicago, USA) was used for data analysis. Cochran-Armitage trend test was used to calculate the association between common variants and AIS. Patients included expression analysis were classified into different subgroups according to the curve pattern or the curve severity. The Student's t test was used to analyze the inter-group comparison of the baseline characteristics and mRNA expression of HSPG2. The relationship between the HSPG2 expression and the curve magnitude of the patients was analyzed by the Pearson correlation analysis. The statistical was set at $p<0.05$.

\section{Results}

\section{Demographic data}

The mean age of patients included in the LDR analysis was $15.3 \pm 3.4$ years (range $10.5-18.8$ years). The mean curve magnitude was $54.3 \pm 11.2$ degrees (range 27-72 degrees). One thousand eighteen patients had curve magnitude more than 50 degrees and thus underwent posterior spinal correction surgery. The mean age of the healthy controls was $18.9 \pm 3.2$ years (range 16.5-22.8 years).

\section{Genotyping of SNVs}

No case of mutation in the reported SNV p.Asn786Ser of HSPG2 was found in our cohort. All the 3336 subjects were found to have genotype TT. A total of 16 SNPs covering HSPG2 were analyzed, with the distribution of minor allele frequency summarized in Table 2. All the SNPs were found to have comparable allele frequency between the patients and the controls.

\section{mRNA expression level of HSPG2}

A total of 98 patients and 28 controls were included for expression analysis. Eight patients and 2 controls were excluded from the analysis due to degradation of total RNA. The expression level of HSPG2 was successfully detected in the paraspinal muscles of 90 patients and 26 controls. There was no significant difference regarding the mean age of the two groups $(15.2 \pm 1.1$ years vs. $15.5 \pm 1.2$ years, $p=0.48)$. The mRNA expression of HSPG2 in patients was comparable with that in the controls $(0.0016 \pm 0.0013$ vs. $0.0019 \pm 0.0012, p=0.29$ ).

Table 2 The allele frequency of 16 SNPs covering HSPG2

\begin{tabular}{|c|c|c|c|c|c|}
\hline \multirow[t]{2}{*}{ SNP } & \multirow[t]{2}{*}{ MA } & \multicolumn{2}{|l|}{ MAF } & \multirow[t]{2}{*}{$p$} & \multirow[t]{2}{*}{ OR $(95 \% \mathrm{Cl})$} \\
\hline & & Patients $(n=1446)$ & Controls $(n=2080)$ & & \\
\hline rs4654770 & $T$ & 0.170 & 0.169 & 0.9262 & $1.01(0.90-1.12)$ \\
\hline rs12040859 & $\mathrm{T}$ & 0.190 & 0.192 & 0.8902 & $0.99(0.87-1.11)$ \\
\hline rs17459139 & $\mathrm{T}$ & 0.165 & 0.167 & 0.8384 & $0.99(0.87-1.11)$ \\
\hline rs7556412 & G & 0.179 & 0.195 & 0.1463 & $0.90(0.81-0.99)$ \\
\hline rs12043008 & G & 0.179 & 0.175 & 0.7164 & $1.03(0.92-1.14)$ \\
\hline rs10799718 & A & 0.385 & 0.371 & 0.278 & $1.06(0.94-1.17)$ \\
\hline rs11810496 & G & 0.393 & 0.390 & 0.8497 & $1.01(0.90-1.12)$ \\
\hline rs2445142 & G & 0.395 & 0.381 & 0.3187 & $1.06(0.94-1.17)$ \\
\hline rs878949 & $\mathrm{T}$ & 0.148 & 0.151 & 0.8051 & $0.99(0.87-1.11)$ \\
\hline rs2501257 & A & 0.395 & 0.386 & 0.5053 & $1.04(0.94-1.16)$ \\
\hline rs6680566 & $C$ & 0.394 & 0.388 & 0.6465 & $1.03(0.92-1.14)$ \\
\hline rs6698486 & G & 0.347 & 0.341 & 0.6487 & $1.03(0.92-1.14)$ \\
\hline rs9426783 & C & 0.443 & 0.436 & 0.62 & $1.03(0.92-1.14)$ \\
\hline rs4654773 & $\mathrm{T}$ & 0.440 & 0.433 & 0.5781 & $1.03(0.92-1.14)$ \\
\hline rs16826053 & C & 0.199 & 0.189 & 0.383 & $1.06(0.94-1.17)$ \\
\hline rs10917067 & $\mathrm{T}$ & 0.107 & 0.116 & 0.2869 & $0.91(0.82-1.01)$ \\
\hline
\end{tabular}




\section{Relationship between HSPG2 and phenotype of the patients}

For the 90 patients included in the expression analysis, 42 patients had curve magnitude more than 60 degrees, thus assigned to the severe curve group. Forty-eight patients with curve magnitude less than 60 degrees were assigned to the moderate curve group. These two groups classified by curve severity were found to have comparable HSPG2 expression $(0.0015 \pm 0.0011$ vs. $0.0017 \pm$ $0.0014, p=0.57)$. And there was no remarkable correlation between the expression level of HSPG2 and the curve severity ( $r=0.131, p=0.71)$, either.

As for the curve pattern, 67 patients had single thoracic curve and the other 23 patients had double major curve. There was no significant difference of HSPG2 expression between the curve pattern groups $(0.0017 \pm 0.0012$ vs. $0.0014 \pm 0.0013, p=0.31)$.

\section{Discussion}

Genetic findings of AIS have been greatly hindered by its clinical and genetic heterogeneity. Previous association studies have revealed many disease-related genes, most of which however appeared inconclusive as indicated by the following replication studies [18, 32, 33]. Carried out in different populations, replication studies have failed to validate the reported associations of ER- $\alpha$, ER- $\beta$, MTNR1b, MATN1, TPH1, IGF1, MMP3, IL6 and TGF- $\beta$ with AIS $[18,19,32,34]$. To the best of our knowledge, LBX1 and PAX1 are the only two susceptible genes that could be successfully validated in Caucasians and Asians with a minimum sample size of over 3000 patients $[20,35]$. The statistical power regarding the associations between these genes and AIS has reached the genome-wide significance that was defined as a $p$ value of less than $5.0 \times 10^{-8}$. Obviously, a large sample size and a rigorous setting of statistical power are key factors to ensure reliable and reproducible findings in genetic studies.

Another difficulty of AIS genetic research lies in that the reported common variants can only explain a small amount of AIS heritability. All the susceptible variants reported by previous GWASs of AIS had an OR value between 1 and 2, leaving over $90 \%$ of the AIS heritability unexplained [20-26]. Since low frequency variants with large effect sizes could be involved in the missing heritability, the role of rare variants in the development of AIS has recently become a widely investigated topic [27-32]. Baschal et al. [31] performed WES in a four-generation idiopathic scoliosis (IS) family and identified the SNV p.Asn786Ser of HSPG2 gene as a novel causative variant of IS. Enrichment of this mutation was then validated in two independent cohorts composed of 241 IS patients [31]. To validate the association of HSPG2 with the development of AIS, we performed the genotyping of p.Asn786Ser in a large cohort consisted of 1752 patients and 1584 controls. No case of mutation was found in this cohort as all the subjects presented the same genotype TT. As for common variants covering HSPG2, none of the 16 SNPs had remarkably different allele frequency between the patients and the controls. Moreover, we observed comparable HSPG2 expression in the paraspinal muscles between the patients and the controls. To summarize, our findings did not support the association of HSPG2 with the susceptibility of AIS in Chinese population.

HSPG2 gene, which has 94 exons, encodes perlecan which binds to basement membrane proteins such as collagen and laminin and to cell surface receptors [36]. Homozygous HSPG2 mutations could lead to a more severe phenotype in human disease, such as SchwartzJampel syndrome Type 1 and Dyssegmental Dysplasia, Silverman-Handmaker Type [37, 38]. Schwartz-Jampel syndrome is reported to be associated with kyphoscoliosis [39]. Baschal et al. [31] therefore speculated that haploinsufficiency of HSPG2 may be associated with a progressive IS and acted as a potential contributor to the phenotype. Aiming to clarify the relationship between HSPG2 and phenotypes of the patients, we classified patients into different subgroups according to the curve pattern or the curve severity. We found that HSPG2 expression was not associated with either the curve severity or the curve pattern. Herein, it appeared that HSPG2 had no effect on the phenotype of the AIS patients.

It is unlikely for the current study to have falsenegative results as our sample size is large enough to detect the potential mutation. The susceptibility genes of AIS may play important roles in the diagnosis and therapy of AIS in the future. We believe that the role of HSPG2 in the development of AIS still needs further investigation. The primary limitation of our study lies in that we did not sequence all the exons of HSPG2. It cannot be excluded that enrichment of other mutations of HSPG2 could play a role in AIS. Besides, the function of p.Asn786Ser should be investigated through in-vivo cellular experiment to clarify its role in AIS.

\section{Conclusions}

HSPG2 gene was not associated with the susceptibility or the phenotypes of AIS in the Chinese population. In future study, functional studies of p.Asn786Ser is warranted to clarify whether this variant can regulate the expression of HSPG2. The whole HSPG2 gene can be sequenced in more AIS patients to identify potentially causative mutations. 


\section{Abbreviations}

AIS: Adolescent idiopathic scoliosis; GWAS: Genome-wide association study; HSPG2: Human heparan sulfate proteoglycan 2; LDR: Ligase detection reactions; SNV: Single nucleotide variant; WES: Whole exome sequencing

\section{Acknowledgements}

We gratefully acknowledge the support of all doctors in our department.

\section{Funding}

The data collection was supported by the Natural Science Foundation of China (No. 81501849, No.81661168013, No.81171672, No.81772304 \& No. 81501932), the experiments and data analysis were supported by Natural Science Foundation of Jiangsu Province (BK20150099), and Nanjing Medical Science and technology development Foundation (Grant No. YKK15059).

\section{Availability of data and materials}

The raw data is available from the corresponding author upon reasonable request.

\section{Authors' contributions}

$X C$ and $X L$ performed the study. XB and SF participated in the experiment and data collection/interpretation for the study. QY and ZZ conceived of the study and participated in its design. ZZ was responsible for coordination, data collection/interpretation and proofreading of the final manuscript. All authors read and approved the final manuscript.

\section{Ethics approval and consent to participate}

Approved by the Institutional Review Board (IRB)/Independent Ethics Committee (IEC) of Nanjing Drum Tower Hospital (The Affiliated Drum Tower Hospital of Nanjing University Medical School) at Zhongshan Road 321, Nanjing 210,008, China. All subjects provided informed consent to take part in the study. Written informed consent was obtained from the parents of the participants in this study that are under 18 years old.

\section{Consent for publication}

Not applicable.

\section{Competing interests}

The corresponding author Zezhang Zhu is a member of the Editorial Board of BMC Musculoskeletal Disorders.

\section{Publisher's Note}

Springer Nature remains neutral with regard to jurisdictional claims in published maps and institutional affiliations.

\section{Received: 5 April 2018 Accepted: 4 January 2019}

\section{Published online: 15 January 2019}

\section{References}

1. Murray DW, Bulstrode CJ. The development of adolescent idiopathic scoliosis. Eur Spine J. 1996;5(4):251-7.

2. Kouwenhoven JW, Castelein RM. The pathogenesis of adolescent idiopathic scoliosis: review of the literature. Spine. 2008;33(26):2898-908.

3. Xu L, Qiu X, Sun X, Mao S, Liu Z, Qiao J, Qiu Y. Potential genetic markers predicting the outcome of brace treatment in patients with adolescent idiopathic scoliosis. Eur Spine J. 2011;20(10):1757-64.

4. Wei-Jun W, Xu S, Zhi-Wei W, Xu-Sheng Q, Zhen L, Yong Q. Abnormal anthropometric measurements and growth pattern in male adolescent idiopathic scoliosis. Eur Spine J. 2012:21(1):77-83.

5. Wang S, Qiu Y, Ma Z, Xia C, Zhu F, Zhu Z. Expression of Runx2 and type X collagen in vertebral growth plate of patients with adolescent idiopathic scoliosis. Connect Tissue Res. 2010;51(3):188-96.

6. Guyot MA, Agnani O, Peyrodie L, Samantha D, Donze C, Catanzariti JF. Cervicocephalic relocation test to evaluate cervical proprioception in adolescent idiopathic scoliosis. Eur Spine J. 2016;25(10):3130-6.

7. Sun $X$, Qiu Y, Zhu Z. Variations of the position of the cerebellar tonsil in adolescent idiopathic scoliosis with severe curves: a MRI study. Stud Health Technol Inform. 2006:123:565-70.

8. Morcuende JA, Minhas R, Dolan L, Stevens J, Beck J, Wang K, Weinstein SL, Sheffield V. Allelic variants of human melatonin $1 \mathrm{~A}$ receptor in patients with familial adolescent idiopathic scoliosis. Spine. 2003;28(17):2025-8 discussion 2029.
9. Miller NH, Mims B, Child A, Milewicz DM, Sponseller P, Blanton SH. Genetic analysis of structural elastic fiber and collagen genes in familial adolescent idiopathic scoliosis. J Orthop Res. 1996;14(6):994-9.

10. Miller NH. Genetics of familial idiopathic scoliosis. Clin Orthop Relat Res. 2007;462:6-10

11. Miller NH, Justice CM, Marosy B, Doheny KF, Pugh E, Zhang J, Dietz HC 3rd, Wilson AF. Identification of candidate regions for familial idiopathic scoliosis. Spine. 2005;30(10):1181-7.

12. Xu L, Xia C, Sun W, Qin X, Qiu Y, Zhu Z. Genetic polymorphism of NUCKS1 is associated with the susceptibility of adolescent idiopathic scoliosis. Spine. 2017; 42(21):1629-34.

13. Xu L, Huang S, Qin X, Mao S, Qiao J, Qian BP, Qiu Y, Zhu Z. Investigation of the 53 markers in a DNA-based prognostic test revealing new predisposition genes for adolescent idiopathic scoliosis. Spine. 2015;40(14):1086-91.

14. Mao S, Xu L, Zhu Z, Qian B, Qiao J, Yi L, Qiu Y. Association between genetic determinants of peak height velocity during puberty and predisposition to adolescent idiopathic scoliosis. Spine. 2013;38(12):1034-9.

15. Inoue M, Minami S, Nakata Y, Kitahara H, Otsuka Y, Isobe K, Takaso M, Tokunaga M, Nishikawa S, Maruta T, et al. Association between estrogen receptor gene polymorphisms and curve severity of idiopathic scoliosis. Spine. 2002;27(21):2357-62

16. Qiu XS, Tang NL, Yeung HY, Qiu Y, Qin L, Lee KM, Cheng JC. The role of melatonin receptor 1B gene (MTNR1B) in adolescent idiopathic scoliosis--a genetic association study. Stud Health Technol Inform. 2006;123:3-8.

17. Ryzhkov II, Borzilov EE, Churnosov MI, Ataman AV, Dedkov AA, Polonikov AV. Transforming growth factor beta 1 is a novel susceptibility gene for adolescent idiopathic scoliosis. Spine. 2013;38(12):E699-704.

18. Takahashi Y, Matsumoto M, Karasugi T, Watanabe K, Chiba K, Kawakami N, Tsuji T, Uno K, Suzuki T, Ito M, et al. Lack of association between adolescent idiopathic scoliosis and previously reported single nucleotide polymorphisms in MATN1, MTNR1B, TPH1, and IGF1 in a Japanese population. J Orthop Res. 2011;29(7):1055-8.

19. Liu Z, Tang NL, Cao XB, Liu WJ, Qiu XS, Cheng JC, Qiu Y. Lack of association between the promoter polymorphisms of MMP-3 and IL-6 genes and adolescent idiopathic scoliosis: a case-control study in a Chinese Han population. Spine. 2010;35(18):1701-5.

20. Zhu Z, Xu L, Leung-Sang Tang N, Qin X, Feng Z, Sun W, Zhu W, Shi B, Liu P, Mao $S$, et al. Genome-wide association study identifies novel susceptible loci and highlights Wnt/beta-catenin pathway in the development of adolescent idiopathic scoliosis. Hum Mol Genet. 2017;26(8):1577-83.

21. Zhu Z, Tang NL, Xu L, Qin X, Mao S, Song Y, Liu L, Li F, Liu P, Yi L, et al. Genome-wide association study identifies new susceptibility loci for adolescent idiopathic scoliosis in Chinese girls. Nat Commun. 2015;6:8355.

22. Sharma S, Londono D, Eckalbar WL, Gao X, Zhang D, Mauldin K, Kou I, Takahashi A, Matsumoto M, Kamiya N, et al. A PAX1 enhancer locus is associated with susceptibility to idiopathic scoliosis in females. Nat Commun. 2015:6:6452

23. Ogura Y, Kou I, Miura S, Takahashi A, Xu L, Takeda K, Takahashi Y, Kono K, Kawakami N, Uno K, et al. A functional SNP in BNC2 is associated with adolescent idiopathic scoliosis. Am J Hum Genet. 2015;97(2):337-42.

24. Kou I, Takahashi Y, Johnson TA, Takahashi A, Guo L, Dai J, Qiu X, Sharma S, Takimoto A, Ogura Y, et al. Genetic variants in GPR126 are associated with adolescent idiopathic scoliosis. Nat Genet. 2013:45(6):676-9.

25. Takahashi Y, Kou I, Takahashi A, Johnson TA, Kono K, Kawakami N, Uno K, Ito M, Minami S, Yanagida $\mathrm{H}$, et al. A genome-wide association study identifies common variants near LBX1 associated with adolescent idiopathic scoliosis. Nat Genet. 2011:43(12):1237-40.

26. Sharma S, Gao X, Londono D, Devroy SE, Mauldin KN, Frankel JT, Brandon JM, Zhang D, Li QZ, Dobbs MB, et al. Genome-wide association studies of adolescent idiopathic scoliosis suggest candidate susceptibility genes. Hum Mol Genet. 2011;20(7):1456-66.

27. Patten SA, Margaritte-Jeannin P, Bernard JC, Alix E, Labalme A, Besson A Girard SL, Fendri K, Fraisse N, Biot B, et al. Functional variants of POC5 identified in patients with idiopathic scoliosis. J Clin Invest. 2015;125(3): 1124-8

28. Buchan JG, Alvarado DM, Haller GE, Cruchaga C, Harms MB, Zhang T, Willing MC, Grange DK, Braverman AC, Miller NH, et al. Rare variants in FBN1 and FBN2 are associated with severe adolescent idiopathic scoliosis. Hum Mol Genet. 2014;23(19):5271-82.

29. Justice CM, Bishop K, Carrington B, Mullikin JC, Swindle K, Marosy B, Sood R Miller NH, Wilson AF. Evaluation of IRX genes and conserved noncoding 
elements in a region on 5 p13.3 linked to families with familial idiopathic scoliosis and kyphosis. G3 (Bethesda, Md). 2016;6(6):1707-12.

30. Haller G, Alvarado D, McCall K, Yang P, Cruchaga C, Harms M, Goate A, Willing $\mathrm{M}$, Morcuende JA, Baschal $\mathrm{E}$, et al. A polygenic burden of rare variants across extracellular matrix genes among individuals with adolescent idiopathic scoliosis. Hum Mol Genet. 2016;25(1):202-9.

31. Baschal EE, Wethey Cl, Swindle K, Baschal RM, Gowan K, Tang NL, Alvarado DM, Haller GE, Dobbs MB, Taylor MR, et al. Exome sequencing identifies a rare HSPG2 variant associated with familial idiopathic scoliosis. G3. 2014;5(2): $167-74$.

32. Xu L, Xia C, Zhu W, Feng Z, Qin X, Sun W, Qiu Y, Zhu Z. Lack of association between AKAP2 and the susceptibility of adolescent idiopathic scoliosis in the Chinese population. BMC Musculoskelet Disord. 2017;18(1):368.

33. Qiu XS, Lv F, Zhu ZZ, Qian BP, Wang B, Yu Y, Qiu Y. Lack of association between the CHL1 gene and adolescent idiopathic scoliosis susceptibility in Han Chinese: a case-control study. BMC Musculoskelet Disord. 2014;15:38.

34. Xu L, Sun W, Qin X, Qiu Y, Zhu Z. The TGFB1 gene is associated with curve severity but not with the development of adolescent idiopathic scoliosis: a replication study in the Chinese population. BMC Musculoskelet Disord. 2016;17:15.

35. Nada D, Julien C, Samuels ME, Moreau A. A replication study for association of LBX1 locus with adolescent idiopathic scoliosis in French-Canadian population. Spine. 2017;43(3):172-8

36. Costell M, Gustafsson E, Aszodi A, Morgelin M, Bloch W, Hunziker E, Addicks K, Timpl R, Fassler R. Perlecan maintains the integrity of cartilage and some basement membranes. J Cell Biol. 1999:147(5):1109-22.

37. Stum M, Davoine CS, Vicart S, Guillot-Noel L, Topaloglu H, Carod-Artal FJ, Kayserili H, Hentati F, Merlini L, Urtizberea JA, et al. Spectrum of HSPG2 (Perlecan) mutations in patients with Schwartz-Jampel syndrome. Hum Mutat. 2006;27(11):1082-91.

38. Ladhani NN, Chitayat D, Nezarati MM, Laureane MC, Keating S, Silver RJ, Unger S, Velsher L, Sirkin W, Toi A, et al. Dyssegmental dysplasia, SilvermanHandmaker type: prenatal ultrasound findings and molecular analysis. Prenat Diagn. 2013;33(11):1039-43.

39. Mukaihara K, Godai K, Yamada T, Hasegawa-Moriyama M, Kanmura Y. Successful airway management using a MultiViewScope handle with a stylet scope in a patient with Schwartz-Jampel syndrome. JA Clin Rep. 2016;2(1):36.

Ready to submit your research? Choose BMC and benefit from:

- fast, convenient online submission

- thorough peer review by experienced researchers in your field

- rapid publication on acceptance

- support for research data, including large and complex data types

- gold Open Access which fosters wider collaboration and increased citations

- maximum visibility for your research: over $100 \mathrm{M}$ website views per year

At $\mathrm{BMC}$, research is always in progress.

Learn more biomedcentral.com/submissions 